\title{
Arbor
}

\section{El Biodeterioro en el Museo}

\section{Nieves Valentín y Rafael García}

Arbor CLXIV, 645 (Septiembre 1999), 85-107 pp.

El biodeterioro de un soporte Histórico es un fenómeno complejo que implica alteraciones de las propiedades fisico-químicas y mecánicas del material por acción de organismos biológicos. A ello hay que añadir las modificaciones del aspecto estético que se producen en los objetos afectados. La intensidad de las alteraciones, se produce en función de los componentes de los soportes y de las condiciones ambientales.

Gran parte de las colecciones que se exhiben en los museos son de naturaleza orgánica, caracterizándose por su alta higroscopicidad. Ello implica un significativo incremento del contenido de humedad del soporte, especialmente, cuando los objetos son expuestos a una insuficiente ventilación y a una humedad relativa superior al 65\%. Bajo estas condiciones, numerosos materiales quedan expuestos al desarrollo de especies de microorganismos. A esta problemática, se une frecuentemente la presencia de insectos que pueden contribuir a la pérdida irreparable de piezas históricas en un breve periodo de tiempo.

\section{Los hongos y las bacterias como contaminantes microbiologicos más frecuentes}

Desde el punto de vista evolutivo, los hongos son organismos más desarrollados que las bacterias. Son estructuras normalmente pluricelula- 
res con un metabolismo complejo. Poseen filamentos llamados hifas que forman el micelio o cuerpo vegetativo. Se desarrollan fácilmente a un $\mathrm{pH}$ entre $4-6$, humedades relativas superiores a $70 \%$ y temperaturas entre $25-30^{\circ} \mathrm{C}$. Las oscilaciones de los parámetros microclimáticos pueden favorecer el desarrollo de las esporas fúngicas.

Los hongos al igual que muchas especies bacterianas producen manchas de diferentes tonalidades, como resultado de los productos que excretan. Entre ellos, se reconocen enzimas tales como la celulasa o diferentes tipos de proteasas y ácidos orgánicos (oxálico, fumárico, acético, láctico, glucónico, glucurónico, etc), los cuales se depositan sobre el soporte modificando sus propiedades químicas y como consecuencia, deteriorándolo

Las bacterias son organismos unicelulares. Generalmente se desarrollan a $\mathrm{pH}$ de $7-8$ y temperaturas entre 25 y $38^{\circ} \mathrm{C}$, aunque muchas especies toleran temperaturas inferiores a $0^{\circ} \mathrm{C}$, otras, como las termófilas, resisten más de $45^{\circ} \mathrm{C}$. Pueden ser aerobias o anaerobias. También las bacterias producen enzimas y ácidos orgánicos e inorgánicos que están

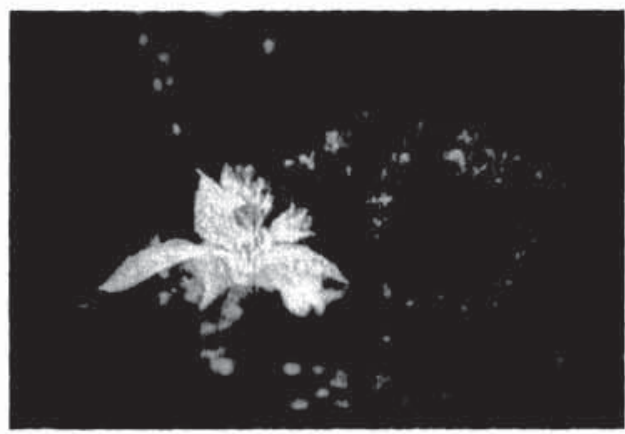

Figura 1. Detalle de contaminación fúngica sobre lienzo protegido con vidrio. implicados en los mecanismos de degradación de los soportes históricos.

La actividad de las diferentes especies de hongos y bacterias se ve favorecida por multitud de factores que incluyen: la humedad relativa, las fluctuaciones de la temperatura, la luz, la naturaleza de los nutrientes del soporte, el contenido de humedad del mismo, las propiedades físicas de la superficie del objeto, el mecanismo de adsorción-emisión de la hu-

medad del material, el $\mathrm{pH}$, la presencia de polvo, el movimiento del aire ambiental y su grado de penetración en el objeto, y las concentraciones de oxígeno y dióxido de carbono en la atmósfera.

El contenido de humedad en un material es uno de los factores más importantes en el crecimiento microbiano que determina la cantidad de agua presente para la germinación de las esporas microbianas. Muchas especies de hongos y bacterias comienzan su desarrollo en función del contenido de humedad sobre la superficie de un objeto. Asimismo, ha de tenerse en cuenta que los microorganismos, durante su desarrollo, producen agua metabólica, la cual incrementa el contenido en humedad de un material, favoreciendo a su vez la multiplicación celular (figura 1). 


\section{El Biodeterioro en el Museo}

Para prevenir el biodeterioro, no es conveniente reducir excesivamente el grado de humedad relativa del medio ambiente. A modo de ejemplo, puede citarse que Erhardt (1994), estudió el efecto de la HR ambiental sobre el deterioro químico de un material celulósico como el papel, y demostró que el grado de hidrólisis de este soporte, se minimiza al reducir la HR. Sin embargo, a baja HR, puede dar comienzo la reticulación o entrecruzamiento de las cadenas de celulosa, fenómeno éste que se produce al eliminarse el agua interfibrilar. Para evitar este fenómeno, Erhardt recomendó una HR entre el $25-50 \%$ como rango óptimo para la conservación del papel.

\section{Factores ambientales que influyen en la contaminación microbiológica de las colecciones}

Existen muchos edificios históricos destinados a museos con graves problemas de deterioro que se encuentran en regiones con climas húmedos, en donde el término medio de humedad relativa anual supera ampliamente el $80 \%$. Para subsanar este problema, los arquitectos de esas zonas han incorporado a los diseños de los edificios unas características y unas necesidades de mantenimiento específicas para hacer frente a la humedad ambiental. Los usuarios de estos edificios también han elaborado unas normas elementales para mantener adecuadamente el ambiente en los mismos. Sin embargo, con el paso del tiempo, muchos de estos edificios y sus zonas adyacentes se han ido modificando para ir adaptándose a las necesidades cambiantes de sus ocupantes. Alguna de esas estructuras se adecuaron para albergar archivos, bibliotecas y/o colecciones de museos. Nuevos aspectos, tales como la seguridad frente a robos, el seguimiento de la normativa de seguridad contra incendios y los controles de plagas, han alterado muy negativamente las previsiones originales para modificar el clima en su interior. De este modo, en muchos museos y archivos se fueron incorporando instalaciones de aire acondicionado, y se aplicaron fumigaciones ambientales con objeto de conseguir microclimas con temperatura y humedad controlada, libre de agentes biodeteriorantes

No obstante, es conocido que los sistemas de climatización son dificilmente sostenibles, económica y técnicamente, a nivel local. Por otra parte, el uso de productos quimicos tóxicos, como fumigantes conllevan riesgos que afectan tanto a los materiales históricos como a los profesionales que trabajan con los mismos. Recientemente, se han adoptado nuevos sistemas alternativos para soslayar estos problemas de conservación. 
Métodos de control con productos tóxicos habitualmente aplicados a objetos históricos.

Dentro de los métodos de desinfección y desinsectación de bienes culturales, se han venido aplicando numerosos procedimientos. $\mathrm{El}$ más común de ellos ha sido la fumigación en cámaras con oxido de etileno. Este producto, puede provocar reacciones químicas que inducen deterioros significativos. Puede reaccionar con los grupos sulfidrilos, de las proteínas, y con los carbonilos e hidroxilos de las celulosas, ocasionando alteraciones de las estructuras de los polímeros. También reacciona con compuestos metálicos, especialmente con el cobre. Todo ello produce cambios en las propiedades físicas y químicas de los soportes tratados. Además, es un producto altamente tóxico.

El timol es un producto mas accesible que se ha venido utilizando habitualmente en forma cristalina como sólido sublimable. Varios estudios indican que no elimina las esporas de hongos ni las células bacterianas. Puede ocasionar alergias e irritación en las vías respiratorias. Se le atribuyen efectos cancerígenos.

Otros químicos como el ortofenilfenol (OFF), tienen un amplio espectro como fungicida y bactericida. El OFF se ha utilizado ampliamente como biocida aplicado a bienes culturales. También se ha incorporado a productos de restauración, adhesivos sintéticos y colas animales. Puede despolimerizar algunos adhesivos. Deteriora los textiles y el papel produciendo cambios de color y envejecimiento de los materiales. No obstante, su toxicidad es menor que la de otros fungicidas incluyendo el pentaclorofenol. Es soluble en etanol. La sal sódica del ortofenilfenol es soluble en agua y presenta mayor grado de toxicidad que el ortofenilfenol.

El formaldehído, se ha aplicado frecuentemente por nebulización, tiene un poder de penetración escaso. Tiene un efecto fungicida limitado y no tiene eficacia como insecticida. Es un buen fijativo del material celular, por ello se considera muy tóxico. Tiene efectos cancerígenos. Los tratamientos con formaldehído se aplican a alta humedad relativa para impedir que se polimerice y que pueda precipitar sobre los materiales tratados formando un depósito blanco. Un producto similar, el paraformaldhehido es un sólido sublimable utilizado como desinfectante. Se comercializa en pastillas de 1 gramo y se utilizan $3-5 \mathrm{gr} / \mathrm{m}^{3}$ aplicados en bolsas de plástico herméticamente cerradas y expuestas a una temperatura de $25^{\circ} \mathrm{C}$ aproximadamente. Con ello se favorece la sublimación. Tiene un factor de riesgo de toxicidad similar que el formaldehído. Los materiales proteicos tratados con formaldehído pierden flexibilidad. Por ello, nunca deben emplearse como desinfectante de 


\section{El Biodeterioro en el Museo}

pergaminos, cueros, pieles y sedas. Incrementa el proceso de corrosión de las tintas ferrogálicas. Es un corrosivo enérgico de los metales y de los vidrios.

El pentaclorofenol, ha sido muy utilizado como fungicida de libros, textiles madera etc. Se ha comprobado que ataca los metales y consecuentemente los pigmentos. Degrada la celulosa del papel y de la madera. Es altamente tóxico por inhalación y por contacto con la piel, por lo que no está registrado como fungicida en muchos países.

Se ha comprobado que una disolución de etanol-agua al $70 \%$ actúa como fungicida de muchos hongos celulósicos y proteicos. El etanol elimina los mohos por deshidratación. El carácter fungicida del producto es menor cuando se aplica etanol absoluto al $100 \%$. Su efecto como bactericida no es muy amplio, por ello para aumentar su eficacia como microbicida y en caso de soportes muy contaminados, suele recomendarse preparar una disolución de etanol al $70 \%$ a la que se le incorpora $0.1 \%$ de ortofenilfenol. Este preparado se aplica por imprimación, pulverización o baño. Posiblemente sea el tratamiento más efectivo y menos tóxico de los químicos expuestos.

Existen tratamientos de desinfección que utilizan antibióticos (penicilina, estreptomicina, actinomicina etc) y/o enzimas (lisozima, tripsina, etc.). Su mayor ventaja es que no son tóxicos. Su mayor inconveniente es que tienen un espectro de acción muy pequeño, por lo que existen numerosas especies microbianas que no son eliminadas por estos productos.

\section{Tratamientos alternativos para el control de microorganismos por medios no tóxicos.}

La literatura muestra que los microbios no crecen cuando el aire que los rodea está en movimiento y hay una humedad relativa baja. Análisis de laboratorio han indicado que este fenómeno depende de la temperatura, el grado de ventilación y de las propiedades físico-químicas de los materiales Valentín y col 1998)

Investigaciones recientes, han demostrado la eficacia de la ventilación sobre el crecimiento microbiano como un método específico de control del biodeterioro en los materiales históricos. Con ello, al aplicar un determinado número de renovaciones de aire por hora en un espacio cerrado, se logra inhibir el crecimiento de hongos y bacterias y se consigue decrecer su actividad tanto en ambientes contaminados como en los materiales históricos.

El uso de sistemas de ventilación pasiva, como alternativa al aire acondicionado y como tratamiento de control de biodeterioro, se está aplicando con resultados satisfactorios en museos y archivos ubicados princi- 
palmente en países de climas húmedos y cálidos que precisan un método seguro y de bajo coste para conservar sus fondos y colecciones.

\section{Insectos implicados en el deterioro de materiales históricos.}

En España, existe una mayor incidencia de insectos que de microorganimos implicados en el biodeterioro de los materiales históricos.

Dentro del gran número de órdenes de insectos existentes en la naturaleza, sólo en seis de ellos se encuentran escasas familias en las que ciertos de sus integrantes atacan a los bienes culturales. De estas especies, sólo algunas están consideradas como plagas auténticamente peligrosas, llegando a destruir por completo los materiales atacados. Otras especies sólo representan riesgos para las piezas si sus poblaciones son numerosas debido a circunstancias especiales.

A continuación se describen algunos de los grupos más peligrosos, poniendo de manifiesto algunos aspectos ecológicos interesantes a tener en cuenta desde el punto de vista de la lucha contra estos insectos en el ámbito de la conservación de bienes culturales.

\section{Termitas. Orden Isoptera}

Forman parte de los grupos de insectos más peligrosos y difíciles de erradicar, especialmente, porque algunas especies, (termitas subterráneas), forman sus nidos primarios fuera del edificio al que posteriormente acceden a través de tuberías, o conducciones eléctricas, para instalar sus nidos secundarios y acceder a los materiales celulósicos localizados en el interior del inmueble.

Las termitas, son insectos sociales. El número de individuos en una colonia varía de una especie a otra, oscilando entre 1000 y un millón. Dentro de las colonias, el rey y reina corresponden a las castas reproductivas y las obreras y soldados a las castas estériles.

Las termitas más comunes incluyen un escaso número de familias:

La familia Rhinotermitidae (termitas subterráneas) son las más peligrosas y difíciles de erradicar. Construyen sus nidos principales en la tierra, en las zonas ajardinadas que rodean los edificios, o en la madera húmeda en contacto con la tierra, vg. en las raíces de los árboles. Reticulitermes lucífugus es la especie mas frecuente en países del área mediterránea. Una humedad baja afecta sensiblemente a las colonias de termitas. Asimismo, la luz les perjudica mucho debido a su falta de pigmentación. Por todo ello, se ocultan en el interior de túneles que construyen, por los que se trasladan fácilmente y donde conservan su humedad manteniéndose ocultas de la luz. Solo el rey y la reina poseen alas para desplazarse durante el vuelo nupcial. Están pigmentados para pro- 


\section{El Biodeterioro en el Museo}

tegerse de la luz. Las obreras y soldados no tienen alas, ni están pigmentados a excepción de la cabeza de los soldados que necesitan salir de los nidos para defender las colonias. Destruyen todo tipo de material orgánico, especialmente si está húmedo y contaminado por microorganismos.

Actualmente, se han desarrollado nuevos sistemas de erradicación de termitas subterráneas basados en el uso de sustancias inhibidoras del desarrollo de estos insectos. El principio de funcionamiento se basa en la difusión de un producto insecticida, el hexaflumuron, que no es tóxico para las personas y que tiene un efecto retardado. Se prepara en forma de cebo, el cual es consumido por las termitas obreras. Mediante el intercambio de alimentos, toda la colonia acaba siendo intoxicada.

El hexaflumuron, inhibe la síntesis de la quitina. De este modo, cuando la termita muda, la nueva cutícula no se forma y sin esta piel que le sirve a la vez de esqueleto el insecto no puede vivir. El producto tiene una acción relativamente lenta, merced a lo cual, el insecticida tiene un acceso lento dentro de la colonia.

Los indivuduos de la familia Kalotermitidae son más fáciles de erradicar ya que los nidos principales se instalan en el edificio y llegan a las salas a través de la madera de los muebles o de los túneles construidos a lo largo de las paredes. Prefieren las maderas blandas. Kalotermes flavicolis y Cyptotermes brevis, son las especies mas frecuentes. Esta última es muy frecuente en el área del Caribe y en las costas de California. En España solo se ha descrito en las Islas Canarias. C. brevis ataca también la madera seca.

\section{Carcomas. Orden Coleoptera}

La mayoría de los insectos más peligrosos desde nuestro punto de vista se encuentran dentro del gran orden de los escarabajos. En la inmensa mayoría de los casos, el peligro lo representan las larvas, siendo en muchos casos lo normal que los adultos se alimenten de polen, néctar o que no se alimenten en toda su vida (Figura 2).
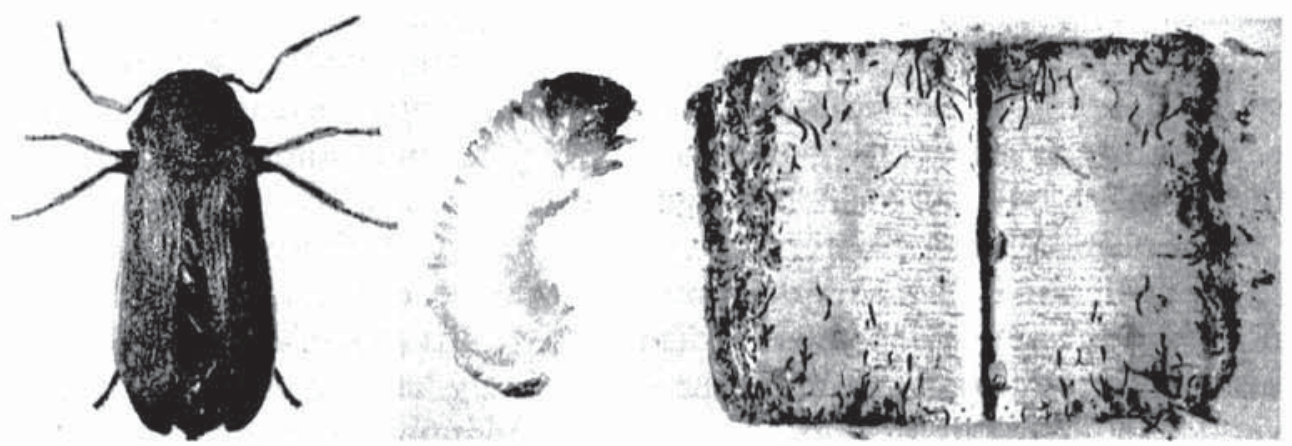

Figura 2. Coleóptero: larva y adulto 
Familia Dermestidae.

Esta familia la componen coleópteros de color negro a pardo, con tamaños comprendidos entre los 1,3 y los $10 \mathrm{~mm}$ de largo. La forma varía desde alargada a oval casi esférica. Las antenas presentan una maza bien diferenciada en su extremo. Las alas son membranosas y están bien desarrolladas.

Las larvas son alargadas. Presentan una o varias generaciones al año, aunque si las condiciones son buenas, se suceden las generaciones continuamente.

Aunque las condiciones ideales para su desarrollo varían de unas especies a otras, por lo general prefieren temperaturas entre 20 y $25^{\circ} \mathrm{C}$ y un 69 $70 \%$ de humedad relativa. En el caso de Dermestes lardarius, las condiciones óptimas para su desarrollo se encuentran en los $18-25^{\circ} \mathrm{C}$ de temperatura y el $70 \%$ de humedad ambiente (Gallo, 1992), siendo su ciclo de vida típico de 3-4 meses (Rust y col. 1996). No obstante, en todos los casos sus ciclos vitales se encuentran fuertemente influenciados por las variaciones de las condiciones ambientales, pudiendo variar desde los 3 meses hasta el año.

En museos y archivos destruyen aquellos bienes culturales que contengan materiales de naturaleza proteica, esencialmente sedas, cueros, pergaminos, momias, plumas, adhesivos utilizados en la restauración, colecciones naturales, etc.

\section{Familia Anobiidae}

Esta familia la componen las denominadas "carcomas pequeñas", insectos de distribución cosmopolita con tamaños comprendidos entre 1 y 9 $\mathrm{mm}$ de longitud con el cuerpo cilíndrico. El color varía entre el pardo rojizo y el marrón oscuro. Presentan una pilosidad corporal generalmente bien desarrollada, en algunas ocasiones formando un dibujo en los élitros.

Las larvas, cuando son sacadas de sus galerías, arquean característicamente el cuerpo en forma de C. Su color es blanco, con segmentos de tamaño uniforme y blandos, recubiertos de sedas espaciadas y de filas de pequeñas espinas. La pupa puede ser libre o aparecer en una especie de capullo de seda. Presenta los caracteres generales del insecto adulto aunque su color es mucho más claro, oscureciéndose según se acerca al final de su desarrollo.

$\mathrm{Si}$ las condiciones ambientales se mantienen estables en unos valores idóneos para el desarrollo de estos coleópteros, el ciclo completo puede ser de apenas dos meses o durar 2-3 años según el contenido de humedad que presente la madera, su calidad y la temperatura durante el desarrollo de la larva. Las condiciones idóneas de humedad y temperatura para el desarrollo de los componentes de esta familia varían 


\section{El Biodeterioro en el Museo}

dependiendo de la especie, pero se encontrarían entre los $22-28^{\circ} \mathrm{C}$ con humedades relativas del ambiente entre el 70-90\% (Gallo, 1992).

Los adultos emergen en primavera y verano, aunque se han constatado emersiones de anóbidos durante todos los meses del año. Su vida es corta y está dedicada en exclusiva a reproducirse. Muchas especies vuelan al anochecer, por lo que se ven atraidas por fuentes de luz.

Las hembras suelen poner los huevos en grietas y rugosidades de los materiales que atacan, por lo que si las superficies están lisas y bien tratadas con barnices, el ataque es improbable. Las larvas eclosionan del huevo por la zona de contacto con la madera y comienzan a excavar sus galerías.

Estos insectos pueden llegar a destruir el soporte por completo. Los agujeros por los que emerge el adulto, en el caso de Anobium punctatum tienen un diámetro de $1-2 \mathrm{~mm}$, en el caso de Xestobium rufovillosum los agujeros de salida del adulto son mayores, con tamaños comprendidos entre los 3-5 mm de diámetro. Las galerías se encuentran rellenas de serrín y restos de excrementos, que en el caso de A. punctatum tienen forma de huso alargado y en el caso de $X$. rufovillosum tienen forma lenticular. Debajo de los agujeros de emersión aparecen acumulaciones de serrín, que en el caso de las especies de Xestobium y Anobium tiene un tacto granuloso.

Familia Lyctidae

Los líctidos son coleópteros de tamaño comprendido entre los 2 y los 5 $\mathrm{mm}$, de forma alargada y aplanada. Pueden presentar un color pardo, amarillo pardo rojizo o negro parduzco. A veces la cabeza puede tener distinto color que los élitros. Las antenas, que se insertan entre los ojos, son alargadas, con una maza terminal.

Las larvas (como en el caso de Anobiidae), cuando se sacan de su galería adquieren una posición curvada. Son blancas y de patas cortas.

Presentan normalmente un ciclo anual, aunque su duración varía dependiendo de las condiciones ambientales y de alimentación.

En el caso de Lyctus brunneus, el desarrollo embrionario es de 8 días con una temperatura de $20-23^{\circ} \mathrm{C}$, reduciéndose a 6-7 días si la temperatura es de $29^{\circ} \mathrm{C}$. Este periodo se alarga hasta los 10-20 días si la temperatura es de $15^{\circ} \mathrm{C}$. Las condiciones ambientales idóneas para el desarrollo de esta especie son de $20-30^{\circ} \mathrm{C}$ y una humedad relativa del $75-90 \%$. Se pueden dar de 1 a 2 generaciones anuales, dependiendo de las condiciones climáticas, pero si las condiciones son desfavorables, el ciclo puede durar 2 años (Gallo, 1992).

En caso de infestación severa, el daño puede ser muy grave. Carcomen la madera en su interior dejando las superficies intactas hasta el momento en que emergen los adultos. Los agujeros de salida tienen un diámetro de 1-2 mm. Las galerías que excavan las larvas presentan una 


\section{Nieves Valentín y Rafael García}

orientación paralela a la fibra de la madera. El serrín que producen estas especies tiene una consistencia similar a la del talco.

Familia Cerambicydae

Lo más característico de la llamada "carcoma grande" es la gran longitud de sus antenas, que se insertan en la escotadura de los ojos. Normalmente son de una longitud igual o mayor que la del cuerpo, siendo poco numerosas las especies con antenas más cortas. En la mayoría de los grupos las antenas se encuentran dirigidas hacia atrás.

Normalmente presentan ciclos de vida anuales, aunque no son raras las especies con ciclos de $2-3$ años de duración.

La larva es aplanada, blanda y blanca o amarillenta. Las mandíbulas son grandes. Carece de patas. La pupa es libre y presenta los rasgos definitorios del adulto.

Hylotrupes bajulus, es la única especie descrita de esta familia que ataca objetos históricos. El tamaño se encuentra comprendido entre 7 y $21 \mathrm{~mm}$ (Zahradnik, 1990). El color es pardo negruzco con una marcada pilosidad blanca. Las antenas nunca son más largas que el cuero, no sobrepasando generalmente la mitad de la longitud del individuo. Es un insecto al que le afec$\tan$ mucho las condiciones ambientales. Por ejemplo a $16,6^{\circ} \mathrm{C}$ y $18 \%$ de humedad, el desarrollo embrionario es de 48 días, de 16 a 17 días si son de 21 a $23^{\circ} \mathrm{C}$ y el $50 \%$ de humedad y tan sólo 6 días si las condiciones son de $31^{\circ} \mathrm{C}$ y del 90 al $95 \%$ de humedad relativa. La duración del ciclo completo puede prolongarse de 3 a 11 años dependiendo de las condiciones ambientales. Los adultos sólo empiezan a ser activos a temperaturas superiores a los $25^{\circ} \mathrm{C}$.

Esta especie provoca graves daños a los objetos que ataca debido a su tamaño y a la duración de su ciclo de vida, de forma que puede llegar a destruir por completo la pieza. Los agujeros de salida son muy variables en cuanto a su forma y tamaño, debido a que el tamaño de los individuos puede ser muy variable, pero por lo general son de forma ovalada, con contornos irregulares y desgastados (Mourier, 1979). Sus diámetros son también variables, estando el radio mayor entorno a los $5-6 \mathrm{~mm}$. El serrín que producen es granuloso y está formado por fragmentos alargados.

«Polillas». Orden Lepidóptera

\section{Familia Tineidae}

Tineola bisselliella es una mariposa de pequeño tamaño, de 8-10 $\mathrm{mm}$ de envergadura. Las alas son lanceoladas y las posteriores presentan una franja ancha de flecos. La larva se desarrolla dentro de un estuche de seda que lleva siempre consigo en sus desplazamientos y que ocul- 


\section{El Biodeterioro en el Museo}

ta pegando excrementos y pequeños trozos del sustrato. Viven sobre sustancias vegetales o animales y pueden llegar a ocasionar daños considerables. Estos consisten en orificios irregulares de $1-2 \mathrm{~mm}$ de diámetro

Es una especie muy común en nuestras colecciones textiles. Su desarrollo se ve muy influenciado por la temperatura. $\mathrm{A} 15^{\circ} \mathrm{C}$ los huevos eclosionan después de 24 días (Hickin, 1985). Este periodo se ve reducido a sólo 7 días si se encuentran a la temperatura óptima para la especie que es de $25^{\circ} \mathrm{C}$ (Mourier, 1979).

\section{El control de plagas}

Los métodos tradicionalmente utilizados en la lucha contra los organismos que deterioran los bienes culturales son, en muchos casos, métodos en los que se utilizan sustancias biocidas tóxicas para las plagas. Éstos se vienen utilizando desde hace mucho tiempo. Aunque su auge se encuentra en este siglo, se empezaron a utilizar de forma sistemática desde el siglo pasado y, ya Plinio en el año 52 a. C., comentaba el uso de productos sulfurosos para tratar casas infestadas por piojos.

A continuación, se describen los tratamientos que se han venido utilizando con mayor frecuencia en el ámbito de la desinsectación de las colecciones históricas y que incluyen diferentes métodos.

\section{Desinsectación con productos tóxicos}

Los tratamientos tóxicos que se utilizan para erradicar insectos abarcan dos tipos de productos: los que actúan por contacto o los fumigantes. Suelen diferenciarse en que los de contacto son sustancias sólidas o líquidas y los fumigantes suelen ser gases o sólidos que sublimen rápidamente. Sobre todo éstos últimos, han sufrido un gran desarrollo durante este siglo por lo espectacular de sus resultados. Debido a que en su origen, la mayoría fueron concebidos para eliminar plagas agrícolas o insectos vectores de enfermedades, son sustancias muy tóxicas, tanto para las plagas, como para casi cualquier forma de vida, incluyendo los humanos. Por este motivo deben manejarse con sumo cuidado y utilizarse de forma racional por personal experimentado y no de forma indiscriminada.

Como consecuencia también de su aplicación original, en muchos casos no existen, o son muy escasos, los datos sobre las toxicidades específicas frente a plagas no agrícolas y las eficacias, dependiendo de los materiales sobre los que se aplican, en su uso para la erradicación de plagas en museos, archivos y bibliotecas. Esto motiva que en muchas ocasiones no sea posible predecir la eficacia de un insecticida al utilizarlo dentro del ámbito de la protección del Patrimonio Histórico.

La toxicidad para el hombre de estos productos, suele quedar enmascarada si se respetan los umbrales de utilización. Los efectos a corto plazo no 
son apreciables, pero todos o casi todos representan un grave riesgo para la salud a medio y largo plazo. La mayoría se han identificado como agentes carcinógenos, teratógenos o productores de enfermedades crónicas debido a su acumulación en el organismo. Este es el caso de gran parte de los fumigantes como el óxido de etileno y el bromuro de metilo entre otros.

Además del problema de su toxicidad, muchas de estas sustancias pueden reaccionar con los materiales de los objetos tratados pudiendo variar sus propiedades físico-químicas, producir cambios en pigmentos y tintes, corrosiones y manchas, entre otras muchas alteraciones. Estas alteraciones pueden ser ocasionadas por el propio producto, o en el caso de hallarse disuelto para una aplicación concreta, por el disolvente o por la mezcla de los dos. Por este motivo deben vigilarse todos estos posibles factores de riesgo, ya que el tratamiento de una pieza con un producto no adecuado puede causarle graves daños e incluso llegar a destruirla.

Asímismo, las piezas tratadas pueden absorber o quedar impregnadas de residuos del producto (óxido de etileno y derivados del arsénico, por ejemplo), lo que hace peligrosa su manipulación sin una limpieza o aireación previa, que en algunos casos puede ser muy larga, con lo que la relativa rapidez del tratamiento con estos productos se puede ver alargada considerablemente por esta causa. La aireación de objetos que han sido tratados con productos como el óxido de etileno, diclorvos o lindano, puede alargarse durante meses e incluso años dependiendo del material. También hay casos en los que materiales tratados hace tiempo con naftaleno y diclorodifeniltricloroetano (DDT), han dado problemas de salud muchos años después.

Además, de un insecticida se requiere que actúe rápidamente y sobre el mayor número de especies posible. El insecticida ideal no existe. Un mismo insecticida tiene mayor eficacia bajo determinadas condiciones de humedad y temperatura, y hay productos que actúan mejor sobre unas especies que sobre otras o sobre unos estadios de crecimiento que sobre otros. La regla general es que los huevos y las larvas sean más resistentes que los adultos, con lo que aun detectando una mortalidad de adultos del $100 \%$, no es garantía de haber acabado totalmente con la plaga, sobre todo si se trata de insectos que horadan túneles en la madera. También algunas de las especies se han hecho resistentes a algunas de estas sustancias, con lo que su aplicación en estos casos sólo sirve para arriesgar la integridad de la pieza y la salud de las personas implicadas.

Por todo esto es muy importante que el responsable de la desinsectación de una pieza tenga la mayor información posible acerca de todos los parámetros implicados en los métodos que se van a utilizar y de las posibles interacciones que pudieran darse con el objeto. Aún disponiendo de datos específicos sobre el insecticida en cuestión, la forma de aplicarlo y el tipo de superficie o lugar donde se aplique influye sobremanera en su 


\section{El Biodeterioro en el Museo}

eficacia. Muchos de ellos pueden aplicarse de varias formas como sprays, aerosoles, polvos, fumigación, microcápsulas, concentrados emulsionables o solubles, etc. Cada una de estas formas de aplicación dependerá de cada problema concreto, y la que es efectiva contra uno de ellos, será poco o nada eficaz frente a otro.

En el Boletín Oficial del Estado número 20 del día 24 de enero de 1984, se establecen, para las sustancias utilizadas como pesticidas, las siguientes categorías:

- De baja peligrosidad $(\diamond)$.- los que por inhalación, ingestión y/o penetración cutánea no entrañan riesgos apreciables. (Naftaleno, piretrinas, paradiclorobenceno).

- Nocivos $(\infty)$. - los que por inhalación, ingestión y/o penetración cutánea puedan entrañar riesgos de gravedad limitada. (Bendiocarbono).

- Tóxicos (0) ). - los que por inhalación, ingestión y/o penetración cutánea puedan entrañar riesgos graves, agudos o crónicos e incluso la muerte. (Diclorvos, lindano).

- Muy tóxicos $(\triangle \infty \infty)$ ). - los que por inhalación, ingestión y/o penetración cutánea pueden entrañar riesgos extremadamente graves agudos o crónicos e incluso la muerte. (Bromuro de metilo, fosfina, óxido de etileno).

La bibliografía muestra numerosos trabajos en los que se ponen de manifiesto las alteraciones físico-químicas que sufren los materiales históricos al exponerlos al efecto de estos agentes químicos. Las alteraciones más significativas ocasionadas en los soportes se describen en las tablas siguientes:

\begin{tabular}{|c|c|c|c|}
\hline PRODUCTO & SINÓNIMOS & COMPOSICIÓN & ALTERACIONES MATERLALES \\
\hline $\begin{array}{l}\text { BENDIOCARBONO } \\
(\infty)\end{array}$ & Ficam & $\begin{array}{l}\text { 2,2-dimetil-1,3- } \\
\text { benzodioxol-4-il } \\
\text { metilcarbamato }\end{array}$ & $\begin{array}{l}\text { Problemas derivados de su uso con agua a } \\
\text { causa de sus productos de hidrolisis, la } \\
\text { metilamina es muy inflamable y un gran } \\
\text { disolvente de sustancias orgánicas. En dos } \\
\text { tintes rojo disperso se producen ligeras } \\
\text { decoloraciones. }\end{array}$ \\
\hline $\begin{array}{l}\text { BROMURO DE METILO } \\
(\triangle 0 O O)\end{array}$ & $\begin{array}{l}\text { Bromometano } \\
\text { Met-0-gas } \\
\text { Terr-o-gas, Maltox }\end{array}$ & Bromometano & $\begin{array}{l}\text { Afecta a materiales tratados o que } \\
\text { contengan azufre (goma, piel, pelo, pluma, } \\
\text { cuero, lana, rayón de viscosa, papel, papel } \\
\text { fotográfico, etc.), altera algunos pigmentos } \\
\text { japoneses en polvo, metales y pigmentos } \\
\text { de plomo. Manchas marrones en la } \\
\text { madera. Hasta la realización de nuevos } \\
\text { estudios, su utilización debe limitarse a } \\
\text { emergencias donde no se pueda utilizar } \\
\text { otro método. Los solventes pueden tener } \\
\text { efectos sobre las piezas que el producto } \\
\text { puro no tiene. }\end{array}$ \\
\hline
\end{tabular}




\begin{tabular}{|c|c|c|c|}
\hline PRODUCTO & SINÓNIMOS & COMPOSICIÓN & ALTERACIONES MATERLALES \\
\hline $\begin{array}{l}\text { DICLORVOS } \\
(\infty \infty))\end{array}$ & $\begin{array}{l}\text { DDVP } \\
\text { Diclorfos } \\
\text { Vapona } \\
\text { Tiras antiinsectos } \\
\text { Vaponita } \\
\text { Nuvan }\end{array}$ & $\begin{array}{l}\text { 2,2-diclorovinil- } \\
\text { dimetilfosfato }\end{array}$ & $\begin{array}{l}\text { Cambios de color en los textiles. Corrosivo } \\
\text { para el acero templado, el hierro y el } \\
\text { hierro negro. Desluce el bronce, el cobre y } \\
\text { la ppata. Produce pátina sobre el zinc, } \\
\text { estaño y plomo. Ablanda gomas, resinas y } \\
\text { plásticos. Ataca tintes rojo ácido y } \\
\text { disperso. Debido a su pequeña presion de } \\
\text { vapor, su penetrabilidad es pequeña y } \\
\text { además se ha comprobado ineficaz contra } \\
\text { los huevos de los insectos. }\end{array}$ \\
\hline $\begin{array}{l}\text { FOSFINA } \\
(0000)\end{array}$ & $\begin{array}{l}\text { Fostoxin } \\
\text { Celphos } \\
\text { Delicia } \\
\text { Gastoxin } \\
\text { Detio-gas-Ex-T } \\
\text { Ex } \rightarrow \text { B }\end{array}$ & Fosfuro de hidrógeno & $\begin{array}{l}\text { Puede provocar corrosiones en el cobre, } \\
\text { aleaciones de cobre, plata y oro. En } \\
\text { general reacciona con todos los metales. } \\
\text { También con el azul ultramarino. Es un } \\
\text { gas peligroso de inmediato a los } 200 \text { ppm. } \\
\text { Fumigante de mercancías agricolas, no se } \\
\text { recomienda su uso en museos, contra } \\
\text { polillas, pieles o muebles. Muy inflamable. } \\
\text { Presenta un olor a pescado podrido por } \\
\text { encima de } 2 \text { ppm. El limite minimo de } \\
\text { explosión es del l,79\% en aire. Poca } \\
\text { solubilidad en agua y grasas. } \\
\text { Espontáneamente inflamable en } \\
\text { presencia de difosfuro de hidrógeno, } \\
\text { reacciona violéntamente con el oxígeno, } \\
\text { nitratos y con los halógenos. }\end{array}$ \\
\hline $\begin{array}{l}\text { LINDANO } \\
(\infty \infty))\end{array}$ & Gammaexano & Gammaexano & $\begin{array}{l}\text { Es potencialmente peligroso para objetos } \\
\text { atacables por ácidos. Deteriora las } \\
\text { propiedades físico-químicas del papel y } \\
\text { de algunas tintas. }\end{array}$ \\
\hline $\begin{array}{l}\text { NAFTALENO } \\
(0)\end{array}$ & $\begin{array}{l}\text { Naftalina } \\
\text { Bolas antipolillas } \\
\text { Cristales antipolilla }\end{array}$ & Naftaleno & $\begin{array}{l}\text { Este compuesto puede recristalizar sobre } \\
\text { los objetos. Con agua produce una } \\
\text { decoloración pardorrojiza en prendas de } \\
\text { lana. Puede reblandecer resinas de } \\
\text { algunos árboles y grasas. También } \\
\text { disuelve las grasas de los especimenes } \\
\text { biologicos dañandolos. Ataca algunos } \\
\text { metales. No es recomendable un uso muy } \\
\text { amplio en museos debida a los riegsos } \\
\text { para la salud. Debe usarse en lugares } \\
\text { donde se pueda alcanzar un nivel estable } \\
\text { del vapor del producto, es decir, en } \\
\text { lugares como armarios que se abran poco. }\end{array}$ \\
\hline $\begin{array}{l}\text { OXIDO DE ETILENO } \\
(\infty \infty \odot))\end{array}$ & $\begin{array}{l}\text { Carbóxido } \\
\text { Oxyfume } 12 \\
\text { Oxirane } \\
\text { Penngas } \\
\text { Epoxietano } \\
\text { ETO } \\
\text { Anprolene } \\
\text { Oxido dimetileno }\end{array}$ & 1,2-epoxietano & $\begin{array}{l}\text { Reacciona con proteínas, sales y celulosa. } \\
\text { Decolora pigmentos al pastel. Disuelve los } \\
\text { adhesivos. La dureza de los materiales } \\
\text { como la lana, papele, algodón y seda baja } \\
\text { entre el } 3 \text { - 10\%. Deja residuos de muy } \\
\text { larga duración en los objetos tratados. Es } \\
\text { un gas altamente inflamable. Hasta que } \\
\text { no se realicen nuevos estudios sobre esta } \\
\text { sustancia, se desaconseja su utilización. } \\
\text { Gran poder de desinsectación de todos los } \\
\text { estadios. }\end{array}$ \\
\hline $\begin{array}{l}\text { PARADICLOROBENCENO } \\
\text { (0) }\end{array}$ & $\begin{array}{l}\text { P-diclorobenceno } \\
\text { P-DCB / 1,4-DCB } \\
\text { PDCB / PDB } \\
\text { PARA } \\
\text { Para-di / Paracida } \\
\text { Paradow }\end{array}$ & 1,4-dicloro benceno & $\begin{array}{l}\text { Afecta al blanco zinc, litopone y pigmentos } \\
\text { encarnados y celulósicos de acetato. } \\
\text { Encoge el poliestireno. Los plásticos como } \\
\text { el estireno, algunas gomas y resinas se } \\
\text { ablandan. Decoloración del azul } \\
\text { ultramarino y algunas tintas. Amarillea el } \\
\text { papel. }\end{array}$ \\
\hline
\end{tabular}




\section{El Biodeterioro en el Museo}

\begin{tabular}{|c|c|c|c|}
\hline PRODUCTO & SINÓNIMOS & COMPOSICIÓN & ALTERACIONES MATERIALES \\
\hline $\begin{array}{l}\text { PARADICLOROBENCENO } \\
\text { (0) }\end{array}$ & $\begin{array}{l}\text { P-diclorobenceno } \\
\text { P-DCB / 1,4-DCB } \\
\text { PDCB / PDB } \\
\text { PARA } \\
\text { Para-di / Paracida } \\
\text { Paradow }\end{array}$ & & $\begin{array}{l}\text { Disuelve las grasas. Es más volátil que el } \\
\text { nafaleno. Es más efectivo, aunque los } \\
\text { problemas son más serios por la rapidez } \\
\text { con que se evapora, lo que puede llevar a } \\
\text { concentraciones muy altas. }\end{array}$ \\
\hline $\begin{array}{l}\text { PIRETRO } \\
(0)\end{array}$ & Piretrinas & Piretro & $\begin{array}{l}\text { Efectos adversos sobre los materiales } \\
\text { tratados desconocidos. Posibilidad de } \\
\text { daños por parte de los solventes. Es uno } \\
\text { de los insecticidas más seguros por su } \\
\text { relativa poca toxicidad. Son muy } \\
\text { inestables y suelen combinarse con otros } \\
\text { insecticidas y compuestos de soporte. }\end{array}$ \\
\hline
\end{tabular}

\section{Métodos no tóxicos}

Existen alternativas a los tratamientos con productos tóxicos entre las que se incluyen los métodos térmicos, las feromonas, microondas y atmósferas transformadas entre otros.

La utilización de métodos térmicos para la desinsectación de los objetos históricos, data de fechas anteriores a los años cuarenta. Pero el desarrollo y el espectacular resultado de los tratamientos químicos, desplazó estos métodos hasta que actualmente, y siguiendo la actual tendencia a utilizar lo menos posible los insecticidas químicos, esas técnicas, han sufrido un nuevo avance. Consisten básicamente en someter las piezas a temperaturas extremas para los insectos. Normalmente suelen ser del.orden de $\operatorname{los} 60^{\circ} \mathrm{C}$ en el caso de utilizar altas temperaturas y entorno a los -20 y $-25^{\circ} \mathrm{C}$ para tratamientos por congelación.

$\mathrm{El}$ someter a un objeto a temperaturas de unos $55^{\circ}-60^{\circ} \mathrm{C}$ es suficiente para acabar con todos los estadíos de desarrollo de la mayoría de las plagas en un tiempo corto. No obstante, entraña graves problemas derivados de la dilatación diferencial en objetos compuestos por materiales diferentes o el reblandecimiento de colas, resinas o pinturas que puedan contener. Aparte de estos cambios, existe el problema de la pérdida de humedad del objeto que, por este motivo, puede sufrir daños (Strang, 1995). Por otro lado, el calor actúa como catalizador acelerando las reacciones químicas de degradación de los materiales. Por ejemplo en el papel de mala calidad, un incremento de temperatura de $5^{\circ} \mathrm{C}$ dobla su velocidad de deterioro. Además, a temperaturas más altas, esta velocidad aumenta más rápidamente (Strang, 1995). 
La utilización de temperaturas bajas, también entraña diferentes problemas. Aunque una temperatura de $0^{\circ} \mathrm{C}$ provoca un estado de coma en muchos insectos, en algunas especies es letal (Strang, 1996). En la práctica, el sistema idóneo es operar entre los $-30^{\circ}$ y los $-40^{\circ} \mathrm{C}$, si bien, hacerlo entre los $-20^{\circ}$ y los $-25^{\circ} \mathrm{C}$ es también muy efectivo (Strang, 1996). No obstante, lo ideal para acabar con los insectos de un objeto, es enfriar lo más rápido, alcanzar la menor temperatura y durante el mayor tiempo que sea posible. Esto es debido a que los insectos presentan adaptaciones dirigidas a sobrevivir en periodos fríos en sus hábitats naturales.

Hay insectos que no llegan a congelarse a temperaturas por debajo de $0^{\circ} \mathrm{C}$. Incrementan la concentración de azúcares y glicerol en sus tejidos, bajando así su punto de congelación. Otros toleran la congelación, controlando la formación del hielo en sus tejidos mediante la síntesis de una nucleoproteína especial en su sangre. La congelación tiene lugar de $-5^{\circ}$ a $-10^{\circ} \mathrm{C}$ en los fluidos extracelulares, mientras que las células se encuentran protegidas de la deshidratación y del daño del hielo por la producción de azúcares y glicerol. Estas especies pueden permanecer así durante meses y reactivarse cuando las temperaturas vuelven a subir. En el caso de Anobium punctatum, el someter sus huevos a temperaturas de $-14^{\circ} \mathrm{C}$, es suficiente para alcanzar una mortalidad del $99 \%$, pero en un experimento realizado por Hansen en 1992 , dos individuos emergieron de huevos sometidos a $-30^{\circ} \mathrm{C}$ (Pinninger and Child, 1996). No obstante, en todos los casos, cuando la temperatura es más baja que su punto de congelación el insecto muere. Estos insectos necesitan también un periodo de aclimatación a las bajas temperaturas, de forma que si la bajada es muy rápida no les da tiempo a protegerse y se congelarían.

Aunque el frío puede servir para alargar la vida de materiales químicamente inestables, aparece el problema del endurecimiento y la pérdida de flexibilidad de los mismos, (sobre todo de los compuestos por polímeros) que se vuelven mucho más frágiles. También pueden darse condensaciones sobre la pieza, tanto al enfriarla como al introducirla en una habitación con la temperatura más alta, lo que originaría que el objeto se humedeciese, con los riesgos que esto entraña.

\section{La aplicación de hormonas.}

Otros métodos, utilizan moléculas sintéticas que imitan hormonas implicadas en la reproducción, el desarrollo o el comportamiento de los 


\section{El Biodeterioro en el Museo}

insectos que se intentan erradicar. El uso de las feromonas se basa en la utilización de estos compuestos para atraer al insecto hacia mecanismos letales o para dificultar el encuentro de los sexos saturando el ambiente con una feromona sintética. Por este motivo, las feromonas que se emplean son las de atracción sexual o las de agrupación.

El principal problema que presentan es su gran especificidad. Aun en el caso de especies estrechamente emparentadas como Anthrenus verbas $c i, A$. flavipes y $A$. sarnicus, las feromonas que producen tienen escaso o ningún poder de atracción cruzada (Pinninger, 1996). Además su síntesis en laboratorio es difícil. Son moléculas complejas que suelen presentar varios isómeros y enantiómeros, los cuales muestran a su vez diferentes grados de atracción. Otra cuestión a tener en cuenta, es que el comportamiento reproductor de los insectos no se basa solamente en la presencia de una determinada feromona en el ambiente, sino que este fenómeno viene precedido de unas condiciones ambientales determinadas que provocan la síntesis de estas sustancias.

Un problema añadido es que (salvo en el caso de las feromonas de agrupación), las feromonas sexuales sólo las produce uno de los dos sexos. Normalmente es la hembra la que las emite para atraer a los machos, con lo que a las trampas acudirán sólo individuos de este sexo.

Por todos estos motivos, la utilización de trampas cargadas con feromonas tienen ninguna o escasa eficacia en la erradicación de plagas. No obstante pueden ser un buen método de vigilancia y de localización de posibles focos cuando se sospecha o se tiene la certeza del ataque de una determinada especie.

Se utiliza también la hormona juvenil. Ésta controla los procesos de metamorfosis y reproducción en los insectos. Es secretada por un par de glándulas endocrinas (los corpora allata), que están controlados a su vez por neurohormonas producidas por el cerebro (Edwards, 1993). Mientras el insecto se encuentra en los estadíos de larva o ninfa, los corpora allata están sintetizando esta hormona, manteniendo una concentración determinada en la hemolinfa del insecto. Cuando se acerca el momento de la metamorfosis, estos corpora allata dejan de sintetizar la hormona y los niveles decaen hasta que desaparece, produciéndose la metamorfosis. A su vez, cuando en un insecto adulto vuelven a existir niveles de hormona juvenil en su hemolinfa, esta funciona estimulando la producción de huevos y controlando otros aspectos de la reproducción. Por lo tanto manteniendo niveles artificiales de la hormona o utilizando moléculas inhibidoras sintéticas, se podrían controlar estos procesos. 
Por último, se utilizan inhibidores de la síntesis de quitina. Son compuestos que interfieren en el control hormonal de este proceso, evitando que la quitina se deposite en el exoesqueleto del insecto. Actualmente en Europa hay varias moléculas comercializadas para este fin como el triflumuron y el lufenuron, que se utilizan para el control de cucarachas. No obstante como en el caso de feromonas y hormona juvenil, éstas moléculas presentan el problema de su especificidad y difícil obtención.

\section{Métodos fisicos. Las radiaciones}

Otro método minoritario es la utilización de radiaciones. Se centra sobre todo en la esterilización de los objetos. Por este motivo, la información disponible acerca de su utilización contra los insectos que deterioran materiales históricos es muy escasa. Provocan la muerte de los organismos vivos al producir cambios en enzimas y otros biopolímeros esenciales para la vida.

Las radiaciones más utilizadas son los rayos gamma. Se producen mediante la desintegración de iones $\mathrm{Co}^{60}$. Este tipo de radiaciones puede ser letal para todos los estadíos de desarrollo de los insectos. En general poseen un alto nivel de penetración, lo que permite el tratamiento de gran número de objetos a la vez. No obstante, esto depende de la energía de los rayos, de la masa del objeto y de la naturaleza del material (Vaillant y Valentín, 1996).

Aunque las dosis necesarias para la desinfección de los materiales históricos se encuentran comprendidas entre los 3 y los $50 \mathrm{KGy}$, la dosis necesaria para la desinsectación es sensiblemente inferior, estando comprendida entre los 0,5 y 1 KGy (Strang, 1996). Si tenemos en cuenta que los daños a algunos materiales se producen ya con dosis de 1-5 KGy (papel) (Strang, 1996), existe un riesgo real de producir daños, sin tener en cuenta los efectos acumulativos de estas radiaciones.

Los principales efectos secundarios derivados del tratamiento con rayos gamma son los producidos por la alta energía que desprenden estas radiaciones. Estas provocan la excitación e ionización de las moléculas, lo que ocasiona la ruptura de enlaces químicos, la formación de radicales y productos como el ozono, altamente oxidante (Strang, 1996). También se produce la ruptura de cadenas laterales y la polimerización de compuestos con dobles enlaces, entrecruzamientos de enlaces poliméricos y la for- 
mación de nuevos dobles enlaces (Vaillant y Valentín, 1996). Todo esto se traduce en un incremento del peso molecular y una pérdida de elasticidad y solubilidad, modificando las propiedades de los materiales, con lo que quedan más expuestos a las alteraciones físico-químicas. Los materiales celulósicos son los más vulnerables, dependiendo de la presencia de lignina y de humedad. Así el papel es mucho más susceptible que la madera. En dosis bajas, pueden causar cambios en los pigmentos naturales y cambios de color térmicamente reversibles en el vidrio (Strang, 1996).

Los rayos $\mathrm{x}$ tienen unos efectos que se pueden comparar con los producidos por las radiaciones gamma, disminuyendo la resistencia física de los materiales y alterando su composición química. Las dosis de $1 \mathrm{KGy}$ pueden provocar cambios de color en objetos pintados.

Otro tipo de radiaciones utilizadas son las partículas cargadas (radiaciones $\beta$ o bombardeo electrónico). Se trata de electrones de alta energía que se consiguen acelerándolos en un campo eléctrico. Poseen un mecanismo de acción muy parecido al de las radiaciones gamma, provocando excitación e ionización molecular, ruptura de enlaces y formación de radicales sobre organismos y materiales. La ventaja sobre los rayos gamma reside en que para conseguir la dosis deseada, el tiempo de irradiación es más corto, además de ser de fácil manipulación. Su principal desventaja es la producción de gran cantidad de calor, a la vez de poseer un bajo nivel de penetración (Vaillant y Valentín, 1996). Los materiales celulósicos se despolimeralizan y, en grandes dosis, se llega a descomponer el polímero de celulosa, con lo que disminuye la resistencia físico-mecánica de estos materiales. También se produce un incremento de cobre y de grupos carboxílicos.

También se emplean las microondas. Son radiaciones de baja energía, con una frecuencia comprendida entre los 500 y los 5000 $\mathrm{MHz}$. Su poder de penetración es muy limitado. Pueden ser absorbidas por materiales que contengan grupos polares o alto contenido de humedad, lo que provoca vibraciones moleculares que producen calor. Los objetos a tratar no pueden contener metales debido al riesgo de calcinaciones. Muchas tintas contienen metales en su composición, lo que puede producir daños en los documentos. La efectividad depende de la frecuencia de la radiación, de la intensidad del campo eléctrico que las produce, condiciones ambientales, especie de insecto y estadío de desarrollo. 
El principal problema es el calor, que produce desecaciones en algunas fibras, que sufren amarilleamientos y llegan a descomponerse, especialmente en la lana. También produce calcinaciones en la madera y pieles, así como reblandecimientos de adhesivos y volatilizaciones de resinas (Vaillant y Valentín, 1996).

\section{Atmósferas transformadas. Los Gases inertes.}

El uso de gases atmosféricos para el tratamiento de piezas históricas atacadas por insectos es un método seguro, tanto para la pieza como para los manipuladores. Diferentes estudios (Valentín y col, 1998), han demostrado que no se producen alteraciones físico-químicas en los soportes y además se puede conseguir el $100 \%$ de mortalidad en todos los estadíos de desarrollo de los insectos, huevo, larva, pupa y adulto.

El término atmósferas transformadas hace referencia a ambientes artificiales, en los cuales se ha eliminado casi por completo el $\mathrm{O}_{2}$, o éste ha sido sustituido por algún otro gas. De esta forma se crea una atmósfera anóxica incompatible con la vida de los insectos, en la que el nivel ideal de $\mathrm{O}_{2}$ se encuentra por debajo del $0,1 \%$.

Para alcanzar concentraciones de $\mathrm{O}_{2}$ lo suficientemente bajas, en todos los casos, hay que aislar la pieza dentro de algún tipo de cámara o bolsa que evite en lo posible la entrada de $\mathrm{O}_{2}$ a su interior. Se pueden utilizar gases inertes como el nitrógeno o el argón, para la sustitución del aire. El nitrógeno, posee la mejor relación entre disponibilidad, eficacia y coste, ya que el Argón tiene un precio más elevado.

El método más práctico es el de utilizar bolsas de plástico selladas, ya que los tratamientos pueden realizarse in situ. La elección de la forma para lograr las condiciones de anoxia deseadas, dependerá sobre todo del volumen, de la permeabilidad al $\mathrm{O}_{2}$ que tenga el material utilizado y de la duración del tratamiento. Además de poseer una baja permeabilidad al $\mathrm{O}_{2}$, el plástico utilizado debe de cumplir otros requisitos importantes. Uno de ellos es ser susceptible de poder ser temosellado de forma rápida y eficaz, además de ser lo bastante flexible para que su manipulación sea sencilla, sin que por ello carezca de resistencia y pueda perforarse con facilidad. Otra ventaja es la transparencia, ya que permite visualizar lo que ocurre dentro de la bolsa en cada momento. También debería de tratarse de un material antiestático, fácil de conseguir y económico.

Hay ocasiones en las que el flujo de gas se debe humectar para evitar los problemas derivados de una desecación de la pieza. Los sistemas de humectación son muy simples y consisten básicamente en hacer pasar el 


\section{El Biodeterioro en el Museo}

flujo a través del agua contenida en un recipiente. Para evitar un exceso de humedad en el gas, se utiliza también gas seco, que se mezcla con el húmedo en la proporción deseada, que dependerá del tipo y condiciones de la pieza.

Las condiciones ambientales a las que se realizan los tratamientos y la especie de insecto que se intenta erradicar influyen en su duración. Incrementos en las temperaturas y descensos en las humedades relativas, provocan un aumento de la respiración del insecto, lo que hace que los tiempos de los tratamientos sean mas cortos. Este es un factor muy importante a tener en cuenta, ya que algunos materiales pueden soportar temperaturas relativamente elevadas y humedades relativas bajas sin deteriorarse, con lo que los tiempos se pueden reducir al máximo, reduciéndose así los costes del tratamiento.

Otro factor muy importante a tener en cuenta en todo tratamiento, es la identificación del insecto, ya que algunas especies son más resistentes que otras a la exposición a atmósferas bajas en $\mathrm{O}_{2}$.

Se ha comprobado a través de diferentes estudios, que cada estadio de desarrollo de una misma especie de insecto muestran distintos grados de susceptibilidad a las atmósferas transformadas. Así los adultos y los huevos, son mucho más susceptibles que las larvas a la exposición a condiciones anóxicas. En todo esto influye, la humedad, la propia anatomía y fisiología del insecto, sus hábitos de vida y su ciclo vital.

\section{La prevencion del biodeterioro}

Todo tratamiento de desinsectación debe realizarse dentro de un plan integral de control de plagas. Este plan integral debe abarcar asímismo el diseño de un plan de conservación preventiva que incluya:

- Análisis del medio ambiente del edificio en general, del entorno y de las salas de exposición en particular.

- Identificación y diagnóstico de los deterioros de las colecciones

- Determinación y evaluación de las causas que amenazan la integridad de las obras.

- Cuantificación del riesgo. 
- Establecer los medios eficaces para detener los riesgos y deterioros de los objetos en función del coste, disponibilidad de medios y de profesionales.

Conocidas las causas de la infestación, deberán establecerse las medidas preventivas para reducir o eliminar el riesgo de nuevas reinsectaciones.

El mantenimiento y esencialmente la limpieza de los edificios es uno de los trabajos prioritarios dentro de la prevención. Es imprescindible garantizar los parámetros adecuados de temperatura, humedad y ventilación.

A pesar de las nuevas metodologías que nos brinda la ciencia aplica$\mathrm{da}$, hay que tener en cuenta que la conservación de nuestro Patrimonio es un compromiso de todos, donde debe existir un enfoque multidisciplinar, imprescindible para conseguir un auténtico avance en la preservación de las colecciones históricas.

\section{Referencias}

EDWARDS, J.: Biorationals and biothechnology - Their future role in the control of insect pests in the urban environment. 1st International Conference on Insect Pests in the Urban Environment. The Organising Committee of the International Conference on Insect Pests in the Urban Evironment. Exeter. (1993): 435440.

ERHARDT, D., Mecklenburg, M.: Relative humidity re-examined. ICOM. Committee for Conservation 10th Triennial Meeting, Washington. (1994): 32-38

GaLlo, F.: Il biodeterioramento di libri e documenti. Centro di Studi per la conservazione della carta. ICCROM. Italy. (1992): 55-80.

Hickin, N.: BоокWоRмs. The insect pest of books. Sheppard Press Ltd. London. (1985).

MoURIER, H., Windind, O., SUnesen, E.: Guía de los animales parásitos de nuestras casas. Omega. Barcelona. (1979).

PinNinger, D., CHILD, R.: WoodWorm - A necessary case for treament? New techniques for the detection and control of furniture beetle. 2nd Intrenational Conference on the Insect Pests in the Urban Environment. The Organising Committee of the International Conference on the Insect Pests in the Urban Environment. Exeter. (1996): 353-359.

PINNINGER, D.: Friends of the dodo - Recent advances in the control of museum insect pests based on detection and targeted treatment. International Institute for Conservation - Canadian Group Workshop, Montreal '96. (1996): 17-27.

RUST, M., Daniel, V., DruziK, J., Preusser, F.: The feasibility of using modified at mospheres to control insect pests in museums. Restaurator Vol 17, 1(1996): 43-60. 


\section{El Biodeterioro en el Museo}

STRANG, T.: Guidelines for museum pest insect control - Low temperature. Canadian Conservation Institute draf note. (1996): 1-7.

Strang, T.: The effect of thermal methods of pest control on museum collections. Preprints, International conference on biodeterioration of cultural property. The organising committee of ICBCP-3. Bangkok. (1995): 199-218.

Valentin, N., GaRcta, R., DE LUIS, O., MaEkaWA, S.: Microbial control in archives, $l i$ braries and museum by ventilation systems. Restaurator Vol 19, 2 (1998): 85-107

VALENTIN, N., VAILlant, M., GUERRERo, H.: Control integrado de plagas en bienes cul. turales de paises de clima mediterráneo y tropical. XI Congreso de Conservación y Restauración de Bienes Culturales. Castellón. (1996): 205-215.

ZAHRADNiK, J.: Guía de los coleópteros de España y de Europa. Omega. Barcelona. (1990). 